\title{
USER EXPERIENCE DESIGN FOR ROUTE CREATION
}

\author{
by \\ Julien Hradecky
}

Hon. BA, Human Geography, University of Toronto, Toronto, Ontario, 2015

\author{
A MRP \\ presented to Ryerson University \\ in partial fulfillment of the requirements for the degree of \\ Master of Digital Media \\ In the program of \\ Digital Media
}

Toronto, Ontario, Canada, 2018

(C) Julien Hradecky, 2018 


\section{AUTHOR'S DECLARATION FOR ELECTRONIC SUBMISSION OF A MRP}

I hereby declare that I am the sole author of this MRP. This is a true copy of the MRP, including any required final revisions.

I authorize Ryerson University to lend this MRP to other institutions or individuals for the purpose of scholarly research.

I further authorize Ryerson University to reproduce this MRP by photocopying or by other means, in total or in part, at the request of other institutions or individuals for the purpose of scholarly research.

I understand that my MRP may be made electronically available to the public. 


\author{
Abstract \\ User Experience Design for Route Creation \\ Master of Digital Media, 2018 \\ Julien Hradecky \\ Digital Media \\ Ryerson University
}

This research project aims to prove the viability of a digital marketplace application where locals can create and sell self-guided routes for tourists. The research will operate under the assumption that a route will need to be sufficiently 'valuable' by metrics that can be defined after an extensive review of literature. My hypothesis is that route creators can design a 'valuable' route in about fifteen minutes. In terms of methodology, I will begin by creating a template for locals to create a route. I will have a group of locals in Toronto create routes and time them in order to test the route creation process. The results disprove that a route with 'value' can be created in fifteen minutes, instead hosts' time needs can vary. Finally, a functioning prototype of the application is made based on user input and feedback. 


\section{TABLE OF CONTENTS}

$\begin{array}{lr}\text { ABSTRACT } & \text { iii } \\ \text { LIST OF FIGURES } & \mathrm{v} \\ \text { LIST OF ABBREVIATIONS } & \text { vi } \\ \text { LIST OF APPENDICES } & \text { vii } \\ \text { 1. INTRODUCTION } & 1 \\ \text { 2. REVIEW OF LITERATURE } & 2 \\ \text { 3. METHODOLOGY } & 10 \\ \text { 4. RESULTS AND DISCUSSION } & 14 \\ \text { 5. CONCLUSION } & 18 \\ \text { APPENDICES } & 20 \\ \text { REFERENCES } & 23\end{array}$




\section{LIST OF FIGURES}

Figure 1: Tourism Experience Value Matrix 5

Figure 2: The Five Phases of Methodology 12 


\section{LIST OF ABBREVIATIONS}

GPS: Global Positioning System

UX: User Experience

ICT: Information and Communication Technologies

MRP: Major Research Paper

MVP: Minimum Viable Product

API: Application Programming Interface 


\section{LIST OF APPENDICES}

Appendix A: Screenshot taken from LikeALocal's homepage. 20

Appendix B: Low-fidelity route visualization using Google Maps. 21

Appendix C: Ryerson Ethics Board Approval - Not Applicable Confirmation 22 


\section{Introduction}

When travelling, tourists often ask: "where do the locals eat?" or "where do the locals go out to drink?" There is a reason this refrain is so commonly heard around the world; tourists desire authentic experiences that expose them to the unique culture of a city (Peak + Skift 2014, p.7). Tourists crave experiences that are outside their norm, rather than over-priced restaurants with menu items they could find at home. When travellers return home, the unique experiences they had and the out-of-the-ordinary sites they saw will be what they excitedly relay to their friends and family. Some elements of travel do not live up to the romanticized ideas we often have about visiting new placesrather, many tourists can find themselves shepherded along with hordes of other travellers to predetermined, over-run sites, listening to the same information regurgitated again and again (Peak + Skift 2014, p.7). These tours can often feel far-removed from the daily experiences of locals in the city.

There are currently limited low-cost ways to travel like a local and discover hidden gems that are off the beaten path. When travelling, there are few convenient options to take a self-guided tour of a city in a way that matches your specific interests. This is because most tours are quite broad and include visits to the main tourist sights. Everyone has unique interests, why is there no way to explore a new place through the lens of your particular interests? Without spending a large sum of money, or a great deal of time on research, there is difficult to have an authentic local experience in a new city. There is also no platform that allows locals living in a city to create unique experiential routes to sell online to tourists and earn a passive income. 
Currently, you have to scour the Internet to try and find the kinds of experiences that align with your specific tastes (Gooch 2016). This is a very time-consuming and repetitive process; not to mention that it is difficult to remember and retain the details of what you have learned when you are actually on your trip (Gooch 2016). When you get to a city you could go on a guided tour. However, due to costs, interests, and time constraints, many people do not use local guides when visiting a new city to discover unique and local experiences (Kow 2016). People enjoy travelling on their own schedule and experiencing things as they explore on their own, and regimented guided tours do not always allow for this.

We are proposing to test a digital marketplace for hosts and visitors to buy and sell low-cost, curated routes that will be used as self-guided tours on a GPS (Global Positioning System)-enabled smartphone application. This would allow locals to use their insider knowledge of a city to create and sell self-navigable routes to visitors on a mobile-based digital marketplace and earn a passive income.

\section{Review of the Literature}

The Travel Industry has steadily grown over the past few years (UNWTO 2017, p.3), with the development of technologies that have made travel much more accessible than ever before. Forecasters attribute this boom to the rising global middle class, which is predicted to grow by another 3 billion by 2031, being led by countries like China and India (Ernst \& Young, 2013). Travel used to be a luxury experience for the wealthy, but is now much more broadly accessible. We can see a rise in trips taken by young people, 
who may or may not have a great deal of disposable income, yet their values align with the need and desire to travel abroad. For example, "in a poll conducted in 2010, about half of Canada's millennials considered travel to be one of the most important aspects of their lives, higher than any other age segment" (CTC Research 2015, p.5). Millennial trips accounted for 20 percent of all travel in 2010 alone, and the number of millennial trips is expected to double or triple by 2020 (CTC Research 2015, p.1). Therefore, it is widely considered an important emerging market segment to focus on, with very large growth forecasts.

The existing research on millennial travellers is extensive and focuses largely on the fact that this customer segment's values are very different from those of other generations or other segments. The largest differentiation between millennial travellers and previous generations of travellers is that they value having unique experiences over traditional travel/tour itineraries: "It is ... important to the young tourists to have the ability to do non-tourist activities, to have contact with local people, and to have the flexibility to change their travel plans" (Demeter, Bratucu, and Palade 2015, p.101). Many firms and organizations have begun shifting their focus towards experiential travel, which has given rise to new tourism destinations around the World. Experiential travel generally aims to provide the tourist with a unique experience that is specific to its location; "experiential travel represents a new layer of opportunity beyond delivering traditional tourism products based on goods and services" (CTC 2011, p.9). For example, the Canadian Government has created tourism industry guidelines for developing its experiential travel offerings nationwide (CTC 2011). This has materialized in adventurebased marketing campaigns such as Travel Alberta's "Remember to Breathe" campaign. 
This campaign gained widespread acclaim from industry experts for enhancing Alberta's appeal with experiential and adventure-travellers, despite not being previously considered a first-tier travel destination (Peak + Skift 2014, p.19).

The rise in millennial travel has simultaneously occurred with the popularization of travel-based sharing economy platforms, which offer up the concept of travelling 'like a local' (Trivett, et al. 2013, p.3). In recent years there has been large growth in sharing economy platforms in the travel sector. For example, companies like Airbnb and Uber can make travel easier for tourists, and oftentimes provide a cheaper alternative to hotels or taxis (Trivett, et al. 2013, p. 22). One of the reasons why this is happening is because of the rise of millennial travellers. Research shows that, "Millennial travelers are some of the most affluent ones in a long time, and they are also confident in knowing what they want... a unique trip no one else can say they had. Their heavy use of social media and portable technology makes obtaining shared economy aspects of their trip lightning fast and easy" (Travel Technology and Solutions, 2015). There is also a documented shift in values amongst millennials from "ownership to access" (Godelnik 2017, p.42). Godelnik (2017) points out that millennials also see the sharing economy as more economically and ecologically sustainable (p.49). The portability and accessibility is key, as "Customers also expect every travel option to be integrated on to a hand-held device" (Woudhuysen 2014, p.6).

Meanwhile, millennials' attention spans are continuously decreasing, as the collective digital ability to focus decreases significantly every year (Mening 2016), and the need for speed has become crucial when interacting with anything digital. These cultural shifts are echoed in Woudhuysen's (2014) call for, "more coherent ways of 
developing and deploying... innovations that can compress both time and trickiness - for both the [customer] and the travel company" (p.7).

Millennials are looking for a different way of travelling, and are changing the industry completely: "Such changes are mostly initiated by young generations, revealing... an increased need for experiences and their authenticity" (Skalska 2017, p.257). Initial research revealed that social media functionalities of travellers' experiences are of particular importance in the future of the tourism industry. As Sotiriadis (2017) notes, "tourism consumers are using [Social Media] platforms and... their behaviour is affected by online reviews in all phases of their tourism experience (planning, during trips and post-consumption)" (p. 216). This shows the connectivity, trust and kinship that travellers already have within existing online communities, where there are insights, advice and tips being exchanged.

Neuhofer, Buhalis and Ladkin's (2013) Tourism Experience Value Matrix (Figure 1) plots the types of experiences that tourists look for in relation to the use of

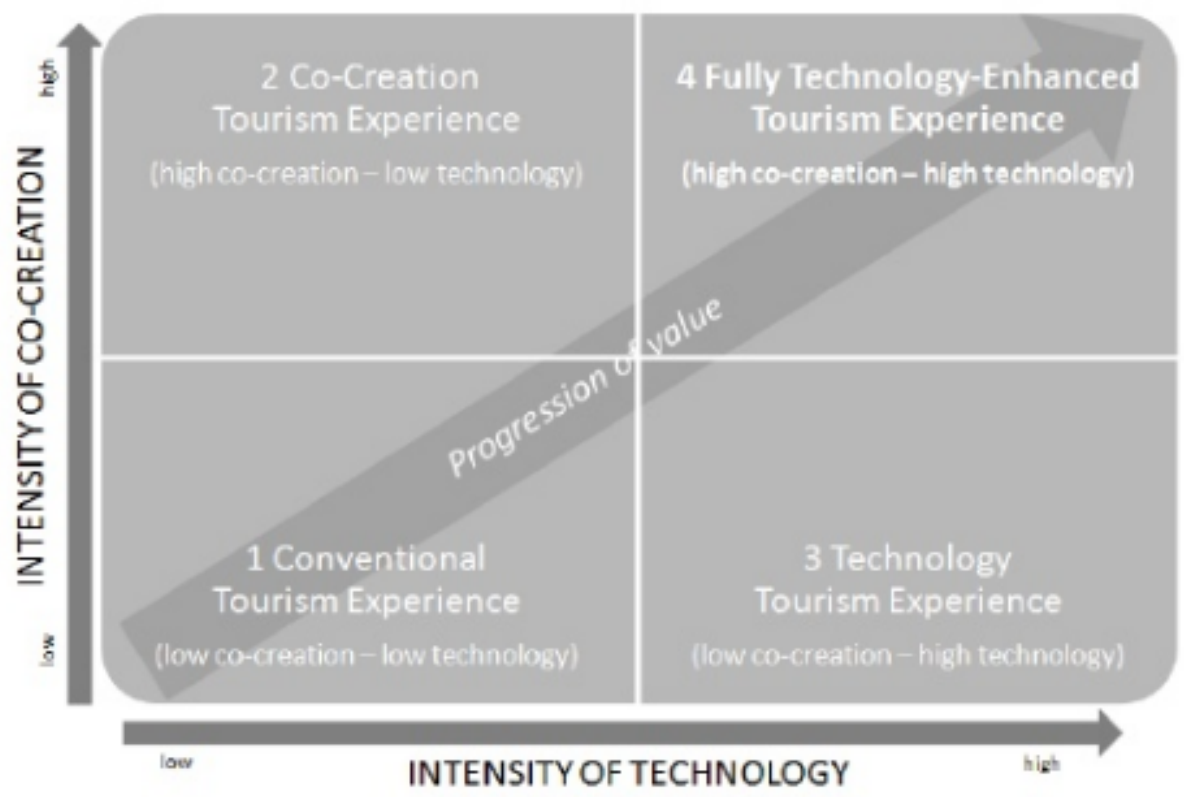

Figure 1 Tourism Experience Value Matrix (Neuhofer, et al. 2013, 550). 
technological capabilities and the amount of co-creation offered. Co-creation can be understood as an opportunity to add value, which allows a tourist to engage with the creation of their own experience with help from other travellers, as opposed to a topdown approach of an agency merely making all tourism decisions without input from consumers (Rihova, Buhalis, Moital \& Gouthro 2014, p.356). The matrix proposes two key factors in offering added value to conventional forms of tourism by integrating, "the potential of both co-creation and ICT in generating meaningful experiences and value" (Neuhofer, et al. 2013, p.549). Neuhofer, et al. (2013) describe technology that adds value to tourism industry products as, "versatile instruments in the enhancement or creation of new types of tourism experiences" (p.549). Whereas the key element of cocreation can be summarized by the fact that, "Consumers are constantly in search of experiences that are particularly valuable to them and co-creation has been proposed as a new means to offer a unique value proposition for consumers" (Neuhofer, et al., p.548). To develop a product for the tourism industry that can be perceived as 'valuable' by consumers it is therefore crucial to provide a "Fully Technology-Enhanced Tourism Experience" (Neuhofer, et al.). Which can be described by Neuhofer, et al. as, "realized when a tourist is highly involved, actively participating and co-creating by using various ICTs to empower this very process. This experience can be considered as the most differentiated and valuable type of contemporary experiences" (p.552).

There are some platforms that offer up alternatives to the traditional 'tour' with sharing economy platforms that provide tours by locals. Trivett et al. (2013) report that, "In the past few years, there has been an explosion of sharing startups that allow residents 
in a destination to act as tour guides" (p. 17). Examples of these platforms include: WithLocals, Airbnb Experiences, Like A Local, Vayable, etc. These are resources for alternative and unique tours, given by locals in many locations around the World. These experiential tours exist in contrast to traditional non-experiential tours, which often visit destinations quickly and shuttle tourists between popular sites, without allowing them to experience elements of the real local culture. This sentiment is what has contributed to the rise of the experiential travel industry. As Jamie Wong, CEO of Vayable, an experiential tour website, illustrates in Peak + Skift's (2014) Travel Report, "Globalization and technology have led to the homogenization of cities, which has resulted in travelers craving locally made and authentic experiences...People want to reclaim what's real. Mass tourism is no longer sufficient" (p.8). While there are many examples of sharing economy platforms that allow locals to offer tours to visitors, allowing them to experience more local and authentic experiences (See Appendix A); the price of these experiences are often just as expensive as their traditional counterparts and can cost even more. To the budget traveller, or traveller that does not enjoy being part of a group tour, this expense often can be considered unaffordable (Kow 2016). Two key elements that are important for guides to provide a succesful tour experience are: the need to keep things personal, and to tell a story (Potter 2016). Hosts taking part in the experiential travel industry "should build ... a variety of activity options so travelers can customize their experience" (Skift 2014, p.31).

The other existing options for gaining local insights into a new city are the travelrelated information resources. These resources are often free; yet generally only provide the traveller with information on well-known or popular tourist sites. It is currently quite 
difficult for users to find local insider knowledge of unique places to visit or experience without spending a great deal of time searching online and planning out their trip manually (Gooch 2016).

Irrespective of the travel industry offering, a constant necessity when providing goods or services is to create 'value' for the end consumer (Woudhuysen 2014). Woudhuysen (2014) urges travel industry firms to, "adopt and apply the principles of 'lean' thinking across IT and operations, in order to create an industry that can better detect, understand and respond to customers' increasingly complex and changing needs" (p.1). This can be done by, “...optimising the online user experience (UX) so that it makes easy the pursuit of customer purpose" (Woudhuysen, p.14). Lean methodology is argued to be most effective to provide the optimal end product for customers in the travel industry: "With lean, travel companies can look forward to rapid rates of new service and app development. They will be able to make more money from cleverly spotted market niches. And, better than they are at present, they will be adept at personalising their offers to the needs of customers as individuals" (Woudhuysen, p.5).

The gap in what is currently available to travellers seems to be a cheaper alternative to a tour, where the main cost is the need to pay a physical guide, and/or tour company. That is why by allowing hosts to create routes once, and sell them on a digital marketplace, allowing tourists to buy and download them based on their interests as a self-guided tour, can lower the overall cost for travellers, as well as decrease the time commitment for locals. With a digital marketplace application, locals do not have to spend hours developing a tour, and physically leading visitors around a city. The only time commitment would be in the initial route creation process. This would allow hosts to 
earn a passive income by creating routes in their city, which visitors would pay for and download, providing hosts with a passive income source. The benefits to the host of course can be more intangible than monetary gain. The benefits of hosting can come in the form of social, political, and cultural capital as well (Griffin 2016, p.47), which can appeal to the hosts desires to portray their hometown as an appealing destination (Griffin 2016, p.58).

Ideally, visitors will be able to arrive in a city and for a very small fee, eliminate the time it takes to do travel research by downloading locally generated unique routes that can be tailored to their specific interests. This will provide a much cheaper, faster, and hassle-free experience for travellers around the world. We believe that creating a sharing economy platform initially directed at a beachhead market of millennial travellers has the potential to truly disrupt the travel industry. This project will focus on uncovering what the route creation process will look like, and what the time commitment might be to create a route that is considered 'valuable', as previously defined, to a potential customer. Research shows that when creative problem solving, some constraints such as time, do not necessarily adversely affect the result: "Constraints... do not necessarily inhibit creative problem solving if the constraints can be manipulated and people are willing to work with these constraints, or work around these constraints, in generating creative problem solutions" (Medeiros, Partlow and Mumford 2014, p.208).

This research will address the previously stated problems faced by travellers, and test the route creation process for time spent versus value created. The research questions that need to be addressed in this MRP are: How much time does a host need to create a route that has 'value'? Can a 'valuable' route be created with a time constraint of fifteen 
minutes? Because if making a route takes too long, or is too difficult to do, the availability and choice of routes for visitors will not materialize. I will also address the question of what the route creation process would look like from a UX design perspective. My initial hypothesis is that fifteen minutes will be enough time to both keep the user's focus, and create a 'valuable' product, with key insights that are 'personal' and/or 'tell a story'. I will test this hypothesis when I conduct the usability testing.

\section{Methodology: Designing to Be Fast, Efficient and Easy to Use}

My initial hypothesis was that the time needed for hosts to create/share a route that can be considered 'valuable' by consumers was under fifteen minutes. My choice to focus on the time it would take hosts to create routes was done to prove the viability of this type of business. My thinking was that in order for an application like this to be successful, we would need a high-quantity of hosts creating routes, but since the cash value hosts would receive from the sale of routes is not particularly high (intended to be some extra income), we would have to ensure that the routes were relatively easy to create, and thus, the amount of effort would have be worth the time spent in terms of the revenue hosts could generate from their route. This would be comparable to thinking about when hosts post a property on Airbnb: if it was a long arduous process to post a property, the chances are that fewer hosts would make the effort to post their properties on Airbnb, and thus, there would be less selection for Airbnb customers to choose from. Therefore, I wanted to test the usability of our route forms in order to ensure that the 
route-creation process would not be a detractor for potential hosts. To me this would be a key part of the viability of our application.

The methodology used to test this hypothesis will use qualitative and quantitative methods of understanding users' habits, time spent, and pain points in the route creation process. The qualitative data will be gathered as user feedback, user generated data inputted into the fields of the route creation document, and assessing whether or not what was created could be considered to have 'value', as previously defined by providing descriptions that include stories or personal insights about what the visitor is experiencing. Quantitative data was collected in the form of time spent per route created. The design of the process must have features that are easy to understand and easy to use to enable the creation of an aesthetically pleasing and unique route in a short period of time.

The methodology used to develop the optimal route creation prototype began by simply creating a fillable document with spaces for the user to input information. The goal was to find the type of information needed from the route creator for them to create a route, and the time it took them to finish. The first iteration of this route creation document began with assumptions based on what I believed to be important information from the literature review for creating a route.

For usability testing, I decided to complete five individual tests for each different version of the route creation form, since five is considered be the "magic number of usability testing" (Martin, 2016) In usability testing, the number of user testers that is widely considered to be the most efficient according to return on investment is five: "The best results come from testing no more than 5 users and running as many small tests as 
you can afford" (Nielsen 2000) According to Sauro, the reason for this is, "The five user number comes from the number of users you would need to detect approximately $85 \%$ of the problems in an interface, given that the probability a user would encounter a problem is about 31\%" (Sauro 2010). In terms of probability, "after the fifth user, you are wasting your time by observing the same findings repeatedly but not learning much new" (Nielsen 2000). Statistically speaking, after conducting three separate tests with a user group of five or more per test, resulting in at least 15 users total, the results should be able to illuminate the probability of being $85 \%$ sure that users will detect any problems or issues that affect 10\% of all users at least once (Sauro 2010). Therefore, the tests should illuminate any problems that affect even a small proportion of users. The decision to use three separate versions that adapted based on user feedback was in keeping with Lean Methodology, which promotes the need to user test and iterate designs based on user feedback.

The overall methodology of this research employed five phases, outlined in

Figure 2. Of the five overall phases, three will incorporate user testing and feedback

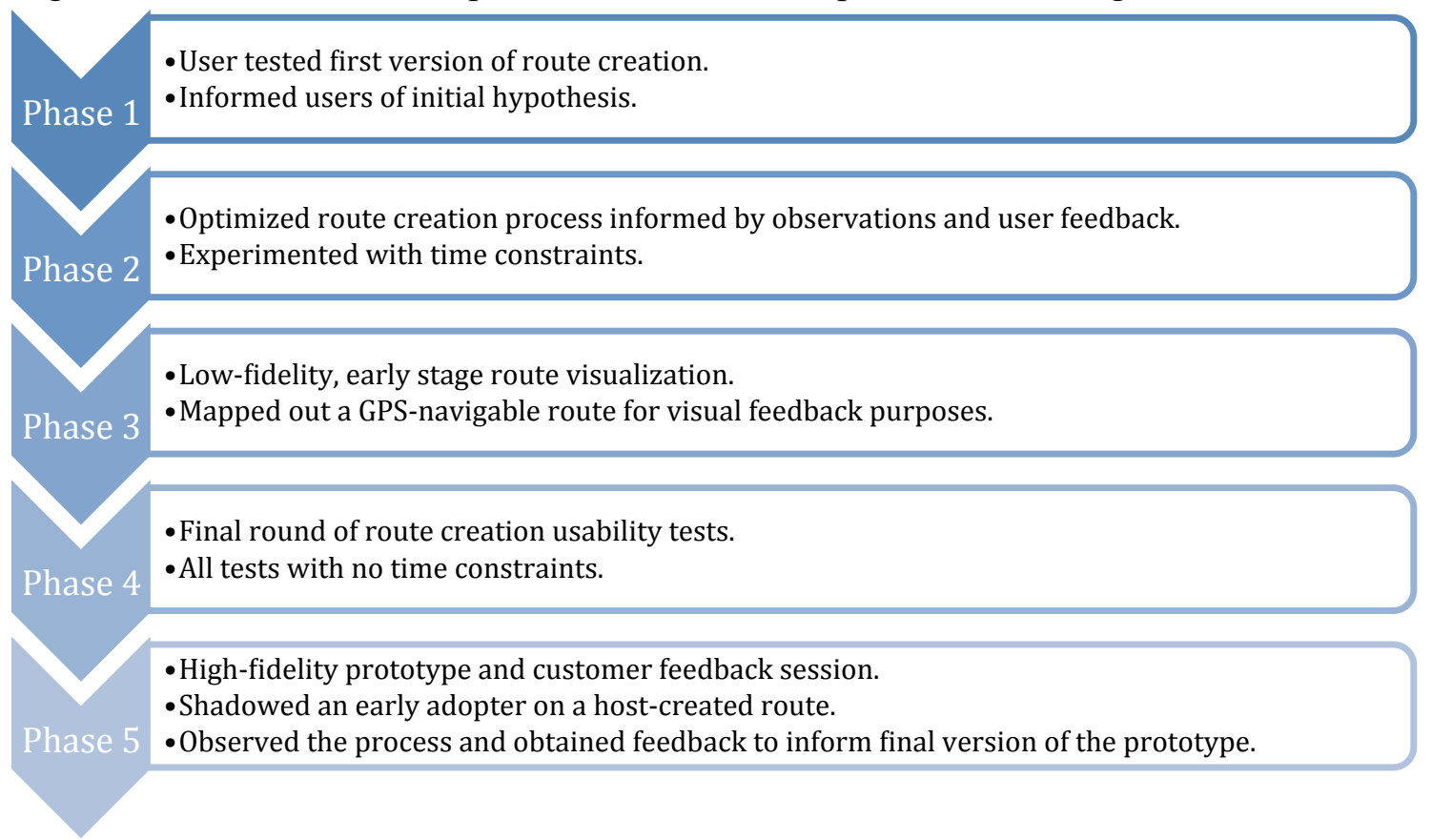

Figure 2 The Five Phases of Methodology. 
sessions pertaining to the route creation process: Phase One, Phase Two, and Phase Four. The remaining two phases, Phases Three and Five, will consist of exercises of visualizing the route to better comprehend and conceptualize the process from the perspectives of both hosts and visitors.

While testing Phase One of the route creation process, I asked fifteen total hosts to time themselves, or timed them myself if I was present while they created their route, letting them know about my fifteen minute hypothesis while describing the task, and thus, imposing a time constraint into the experiment. The hosts selected were individuals in the millennial demographic. Phase Two implemented host feedback and observations into the route creation document, to further streamline the process. The third phase of user-testing incorporated feedback from hosts and information that was gained by plotting the routes into mapping software and optimizing the route. Phase Four incorporated more host feedback and attempts were made to streamline the process further, as well as withholding informing some hosts about my initial hypothesis. After routes were created in the third iteration of the route creation document, a particularly 'valuable' route was chosen to act as an example route. I then asked a potential early adopter, someone who previously expressed interest in our idea and fit within the millennial demographic, if they would test this example route with me to provide feedback and contextualize what the experience would be like for visitors using the application. The early adopter agreed. We went on the route, and I shadowed the visitor, asking questions and receiving feedback. This feedback was then later used for the more 
polished prototype that was developed to create a more streamlined and engaging user experience for the visitor in Adobe XD.

\section{Results and Discussion}

\section{Phase One: Route Creation Usability Testing}

In Phase One, I developed the route creation document based on my review of literature and assumptions made about what information would likely be needed to create a route and test the fifteen-minute hypothesis. The document was created in Microsoft Word, with space for the user to input up to ten locations on their route. I asked the users to create a route with anywhere between five and ten individual locations. This decision was made based on reviewing Airbnb Experiences that were available in Toronto, which generally have between five and ten locations on experiences that are offered (Airbnb Experiences, 2018). I informed the first round of users of my hypothesis -- that a route could be created in fifteen minutes or less; thus creating a time constraint. I found that this led to users spending between 15 and 30 minutes on average to create a route, meaning that users were aware of how much time they were expected to spend on this task, but that the constraint could be manipulated (Medeiros, et al. 2014). Observing one user as they filled out the document, the first thing they did after reading the instructions was to scroll to the bottom to see the full length of the document. Unfortunately most users did not write very extensive descriptions of the locations in the "description" section for each point. The results generally took the form of a path with waypoints, where the descriptions and insights did not really take precedent. I suspect that this was due to their conception that this process could be done very quickly. This round of user 
testing did not produce an end product with the type of 'value' that was considered desirable, and so steps were taken to alter the route creation process based on feedback and user observations in order to generate a better result.

\section{Phase Two: Optimizing and Continued Testing of the Route Creation Process}

One change that was made in the second version of the route creation document was to add page numbers. The page numbers were formatted as, "Page X of $\mathrm{Y}$ ", in the bottom right-hand corner of each page. This was done to function as a de facto "progress tracker" (Babich 2016), a key trend and feature in UX design, which was implemented to inform the user of where they were in the process and what was left for them to finish. This is a proven method of helping those with short attention spans fill out profiles online (Mening 2016). One feature of the document that I was able to gain more insight into was a space that was created for the user to write the time it took them to create the route at the end of the document. Unfortunately since the document had space for users to input up to ten locations, and the average number of locations in a route was 7.5 after the second phase, some users did not see this field because they did not reach the end of the document. Another important change in this phase was to not tell all users about the fifteen-minute hypothesis and compare the efficacy of the time constraint. Since I was not getting 'valuable' outcomes, I decided to experiment with the users' expectations of time commitment. Three users were told that a route could probably be created in fifteen minutes beforehand, and two were not. This resulted in three users spending an average of one hour on their route creation, and two users spending an average of 23 minutes on their route. Only one user spent approximately 15 minutes on their route, with the others 
spending either double, or quadruple that amount of time. The routes that were created in around one hour were far more detailed than the routes that were made in less than 30 minutes. The routes that were created in an hour were far closer to the type of offering that could be considered 'valuable' described in the Review of Literature.

\section{Phase Three: Low-Fidelity Route Visualization}

Once several routes were created, I began to map some of the more 'valuable' routes in a GPS-navigable itinerary on Google Maps to visually see a MVP low-fidelity version of the route (see Appendix B). Some of these low-fidelity routes were shared with the users to give them visual acknowledgement and feedback that what they had created would be tangible. This was done to address the fact that there was often feedback suggesting this be added. For example, one user is quoted as saying, "A map tool where you could draw the route and highlight sights would be [great]". By sharing the mapped route with the route creator, this addresses the desires of users and provides them with an interactive way of visualizing their creation. This visualization phase was also useful in understanding the existing abilities and limitations that Google Maps has when creating a personalized route or map. This was an effective method of visualizing a low-fidelity MVP version of a route after the route creator had provided locations and information beforehand.

\section{Phase Four: Final Route Creation Usability Tests}

In the third iteration of the route creation document, some changes were made based on feedback that suggested some of the fields be turned into boxes, where users 
could more clearly see where text needed to be inputted. For each destination on the route, the "location", and "hours" sections were eliminated in this version. User feedback had stated that a large portion of time was spent searching for addresses of businesses to input into the "location" section of the form. All users used Google and Google Maps simultaneously while creating their route. Some users copy and pasted the weekly hours of operation for businesses from Google into the form as well. Both of these steps took up too much time, and were eliminated. Most notably, in this iteration of the route creation document, I did not inform any users of the fifteen-minute hypothesis beforehand, thus eliminating the time constraint completely. This led to the users naturally spending more time on writing descriptions and providing insights in their route. Users spent one hour on average to create a route. The routes created in this final version of the document were much more aligned with what can be considered 'valuable' in that they offered personal insights and/stories with the ability of co-creation on a technological platform.

\section{Phase Five: Prototype and Product Walkthrough}

After receiving user feedback on the route creation process I began to work on a mobile-based prototype for the application with the intention of doing a live walkthrough of a route with a potential early adopter. I asked an early adopter if they would be interested in going on a free route that was created by a local in Toronto. I gave the user the names and descriptions of some of the routes that were considered the most 'valuable', and offered a diversity of sights and experiences within them. The user made a selection from the options that were offered, and I began to make a more polished, 
functioning mobile-based prototype that featured this particular route. I created the prototype in Adobe XD, which does not allow for GPS navigation. So the user had the prototype open on their smartphone, while I followed with the earlier low-fidelity visualization of the map that was created on Google Maps. This allowed me to provide directions to the user between locations, while they had access to the UX and hostgenerated insights. Along the route, I received feedback for features and functions that the user wanted, or expected if this were to be developed into a fully functional digital application. I then used this feedback to further alter the polished prototype of the UX design of this application. Obviously this represented a first step in user testing the UX design of the prototype, which would need to be followed by additional test subjects to further test the design.

\section{Conclusion}

After obtaining a great deal of user feedback on the host-side of the route creation process, and some feedback on the user side as well, the prototype for a digital marketplace application was developed. The MVP was developed using Lean Methodology and contemporary UX design principles. Observing users' habits disproved my hypothesis that a 'valuable' route could be created in fifteen minutes or less. Though the task of putting together a route with between five and ten destinations, and providing very brief descriptions was achievable generally. Imposing time constraints on the host creators adversely affected the quality and 'value' of the routes created; yet, more time spent did not necessarily correlate to added 'value'. This leads to the conclusion that 
route creators need to spend as much time as they see necessary to develop a route if they are to create a product that can be considered 'valuable', and every individual's time needs may vary. However, the end product suffered in quality when the user only spent between 15 and 30 minutes on creating a route, so that is an insufficient amount of time. Therefore, we would suggest spending a minimum of 45 minutes creating a route. Additional research should be conducted once there is a fully functioning application to test how including features like spell check, an interactive map, and perhaps Google's APIs for populating business hours and addresses can affect the route creation process. These results can be useful for any entrepreneur who is interested in leveraging the growing trends of shared economy, mobile applications and experiential travelling to start a new venture. 


\section{Appendices}

\section{Appendix A}

Screenshot taken from LikeALocal's homepage (LikeALocal 2018). This image targets

millennials that want to experience a city and culture like a local - the epitome of experiential travel.

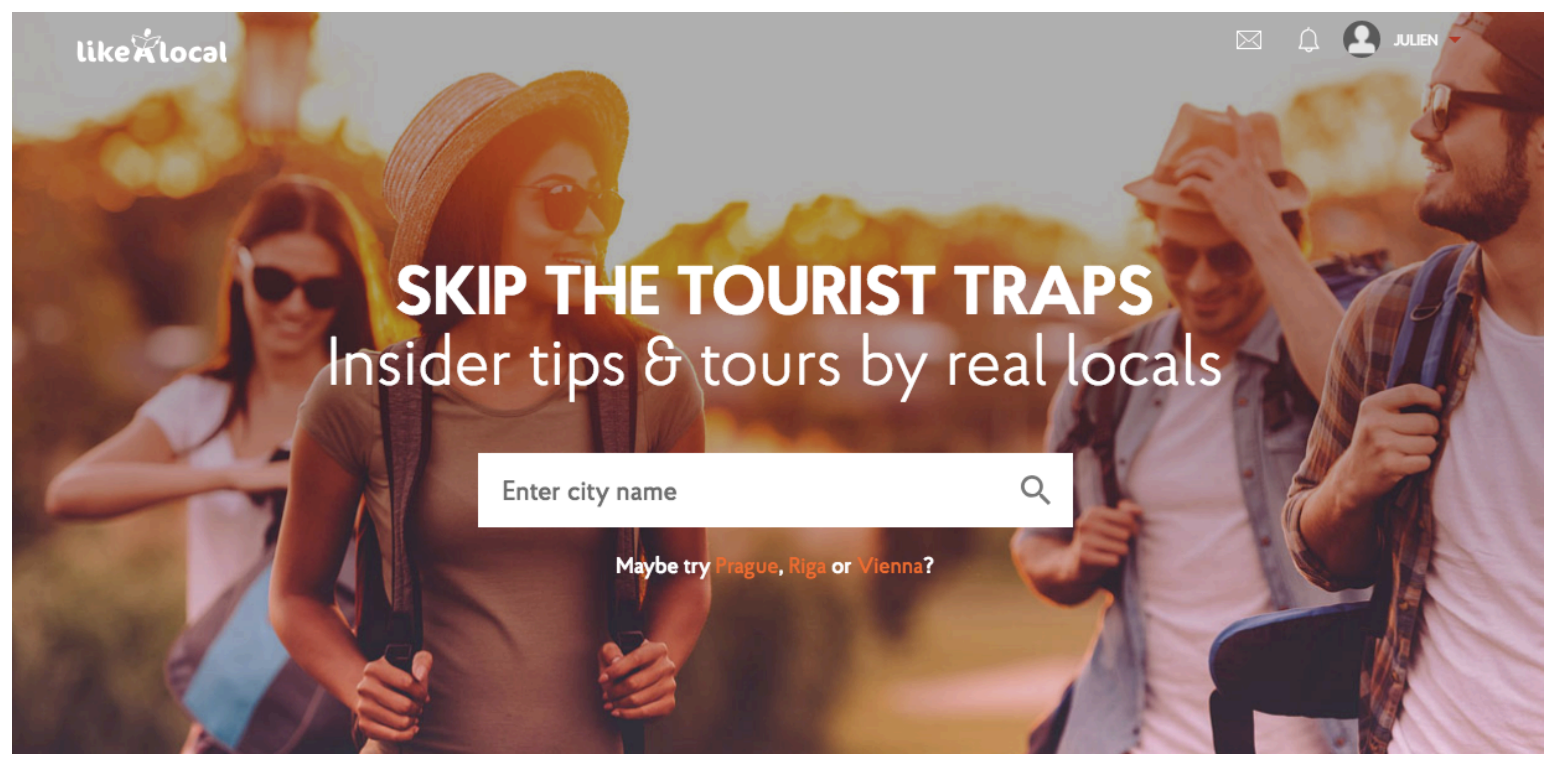




\section{Appendix B}

Low-Fidelity Route Visualisation using Google Maps.






\section{Appendix C}

\section{Ryerson Ethics Board Approval - Not Applicable Confirmation.}



Ryerson Home > Online Ethics Submission and Review System > Protocol View

\section{Email sent to applicant on June 20, 2018 07:56:50 AM}

From: rebchair@ryerson.ca

To: jhradecky@ryerson.ca, ,aozcan@ryerson.ca, tsadek@ryerson.ca

Cc: rebchair@ryerson.ca

Sc: rebchair@ryect: Ethics Application - No REB Review Required

Date: June 20, 2018 07:56:50 AM

Re: REB 2018-253 Routestr - A digital marketplace application for millennial tourists.

Dear Julien Hradecky,

The Research Ethics Board has determined that your protocol does not require its review. Thank you for submitting your application for ethics review for the above noted project. Based on the information provided it has been determined that the project does not require ethics review or approval. As you will be conducting meetings with individuals who are not themselves the focus of the research, but who are authorized in the course of their employment/expertise, to provide data about the mobile app creation to which your study explores, this study does not fall under the TCPS2 definition of research with human participants.

If you have any questions regarding your submission or the review process, please do not hesitate to get in touch with the Research Ethics Board (contact information below).

Record respecting or associated with a research ethics application submitted to Ryerson University.

NOTE: This email account (rebchair@ryerson.ca) is monitored by multiple individuals. If you wish to contact a specific member of the Research Ethics Board, please do so directly.

Yours sincerely,

Dr. Patrizia Albanese, PhD

Chair, Ryerson University Research Ethics Board

(416) $979-5000$ ext. 6526

palbanese@soc.ryerson.ca

rebchair@ryerson.ca

http://www.ryerson.ca/research

Dr. Asher Alkoby, LL.B., PhD

Vice-Chair, Ryerson Research Ethics Board

(416) $979-5000$ ext. 2491

aalkoby@ryerson.ca

http://www.ryerson.ca/research

Toni Fletcher, MA

Research Ethics Co-Ordinator

(416)979-5000 ext. 7112

toni.fletcher@ryerson.ca

Zakiya Atcha, MSW

Research Ethics Co-Ordinato

(416)979-5000 ext. 4841

zakiya.atcha@ryerson.ca

Print Email Close Window 


\section{References}

Airbnb Experiences. (n.d.). Retrieved August 16, 2018, from https://www.airbnb.ca/s/ Toronto--ON/experiences?refinement_paths[]=/experiences\&query=Toronto, ON\&place_id=ChIJpTvG15DL1IkRd8S0K1BVNTI

Babich, N. (2016, April 26). Progress Trackers in UX Design. Retrieved from https://uxplanet.org/progress-trackers-in-ux-design-4319cef1c600Babich 2016

CTC Research. (2015). Canada Millennial Domestic Travel Summary Report (pp. 1-14, Rep.). Canadian Tourism Commission. Retrieved from https://www.destinationcanada.com/sites/default/files/201611/Programs_MillennialTravel_DomesticReport_EN.pdf.

Demeter, T., Bratucu, G., \& Palade, A. (2015). Dynamics of the youth travel market on a global level. Bulletin of the Transilvania University of Braşov Series V: Economic Sciences, 8(57), 5th ser., 95-106. Retrieved from http://webbut.unitbv.ro/BU2015/Series V/BULETIN I PDF/13_Demeter_T.pdf

Ernst \& Young. (2013). Hitting the Sweet Spot: the growth of the middle class in emerging markets (Rep.). Retrieved https://www.ey.com/Publication/vwLUAssets/Hitting_the_sweet_spot/\$FILE/Hitti ng_the_sweet_spot.pdf 
Godelnik, R. (2017). Millennials and the sharing economy: Lessons from a 'buy nothing new, share everything month' project. Environmental Innovation and Societal Transitions, 23, 40-52. doi:10.1016/j.eist.2017.02.002

Gooch, D. (2016, September 02). Why is it so damn difficult to organise a holiday? Retrieved from https://medium.com/planet/why-is-it-so-damn-difficult-to-organisea-holiday-ff99773359b4

Griffin, T. (2016). Immigrant hosts and intra-regional travel. Tourism Geographies, 19(1), 44-62. doi:10.1080/14616688.2016.1169314

Kow, N. (2016, January 19). How to adapt your tours for budget travellers. Retrieved May 23, 2018, from https://www.trekksoft.com/en/blog/5-ways-to-adapt-yourtours-for-a-budget-traveler

LikeALocal. (n.d.). Like a Local Guide. Retrieved August 12, 2018, from https://www.likealocalguide.com/

Mansoori, Y. (2017). Enacting the lean startup methodology: The role of vicarious and experiential learning processes. International Journal of Entrepreneurial Behavior \& Research, 23(5), 812-838, https://doi-org.ezproxy.lib.ryerson.ca/10.1108/IJEBR$\underline{06-2016-0195}$ 
Martin, E. (2016, June 16). Why 5 is the magic number for UX usability testing. Retrieved from https://www.invisionapp.com/blog/ux-usability-research-testing/

Medeiros, K. E., Partlow, P. J., \& Mumford, M. D. (2014). Not too much, not too little: The influence of constraints on creative problem solving. Psychology of Aesthetics, Creativity, and the Arts, 8(2), 198-210. doi:http://dx.doi.org.ezproxy.lib.ryerson.ca/10.1037/a0036210

Mening, R. (2016, October 12). Designing for short attention spans. Retrieved May 1, 2018, from https://www.webdesignerdepot.com/2016/10/designing-for-shortattention-spans/

Neuhofer, B., Buhalis, D., \& Ladkin, A. (2013). Experiences, Co-Creation and Technology: A Conceptual Approach to Enhance Tourism Experiences. In Cauthe 2013: Tourism and Global Change: On the Edge of Something Big (pp. 546-555). Cauthe. Retrieved from https://www.academia.edu/2703085/Neuhofer B. Buhalis_D._and_Ladkin_A._2013._Experiences_Co-creation_and_Technology_ A_conceptual_approach_to_enhance_tourism_experiences?auto=download

Nielsen, J. (2000, March 19). Why You Only Need to Test with 5 Users. Retrieved from https://www.nngroup.com/articles/why-you-only-need-to-test-with-5-users/ 
Nielsen, J. (2012, June 4). How Many Test Users in a Usability Study? Retrieved from https://www.nngroup.com/articles/how-many-test-users/

Peak + Skift. (2014). The Rise of Experiential Travel (Rep.). Retrieved https://skift.com/wp-content/uploads/2014/06/skift-peak-experiential-travelerreport1.pdf

Potter, E. (2016, January 05). 10 Tips for Being a Good Tour Guide. Retrieved from https://savingplaces.org/stories/10-tuesday-tips-good-tour-guide\#.W3RNxpNKjpA

Rihova, I., Buhalis, D., Moital, M., \& Gouthro, M. (2014). Conceptualising Customer-tocustomer Value Co-creation in Tourism. International Journal of Tourism Research, 17(4), 356-363. doi:10.1002/jtr.1993

Sauro, J. (2010, March 8). Why you only need to test with five users (explained). Retrieved from https://measuringu.com/five-users/\#many

Skalska, T. (2017). Sharing Economy in the Tourism Industry: Opportunities and Threats. Central European Journal of Social Sciences and Humanities, 4(54), 248260. Retrieved May 21, 2018, from https://cejsh.icm.edu.pl/cejsh/element/bwmeta1.../c/21_PDFsam_KNUV_54_web.p df. 
Sotiriadis, M. D. (2017). Sharing tourism experiences in social media. International Journal of Contemporary Hospitality Management, 29(1), 179-225. Retrieved from http://ezproxy.lib.ryerson.ca/login?url=https://search-proquestcom.ezproxy.lib.ryerson.ca/docview/1860054313?accountid=13631

Travel Technology and Solutions. (2015, September 28). The Impact of the Sharing Economy on Modern Travel. Retrieved from http://www.tts.com/blog/the-impactof-the-sharing-economy-on-modern-travel/

Trivett, V., et al. (2013, December). What the Sharing Economy Means to the Future of Travel (Rep. No. 7). Retrieved May 19, 2018, from Skift website: http://skift.com/wp-content/uploads/2014/07/skift-what-the-sharing-economy$\underline{\text { means-to-the-future-of-travel.pdf }}$

UNWTO. (2017). UNWTO Tourism Highlights 2017 (Rep.). UNWTO. Retrieved from https://www.e-unwto.org/doi/pdf/10.18111/9789284419029.

Woudhuysen, J. (2014). Cleared for take-off: Strategies in Lean IT and how they're relevant to the travel business (Publication). Amadeus. Retrieved from https://amadeus.com/documents/en/blog/pdf/2014/10/lean_it.pdf. 
